Research Article

\title{
Experimental Study on SSRC under Eccentric Compression
}

\author{
Qingfu Li $\left(\mathbb{D}\right.$, Tianjing Zhang $\left(\mathbb{D}\right.$, Yaqian Yan $\mathbb{D}^{D}$, and Qunhua Xiang \\ School of Water Conservancy Engineering, Zhengzhou University, Zhengzhou 450001, China \\ Correspondence should be addressed to Yaqian Yan; yyq@zzu.edu.cn
}

Received 15 June 2021; Accepted 11 November 2021; Published 1 December 2021

Academic Editor: Rahul V. Ralegaonkar

Copyright (c) 2021 Qingfu Li et al. This is an open access article distributed under the Creative Commons Attribution License, which permits unrestricted use, distribution, and reproduction in any medium, provided the original work is properly cited.

The use of stainless steel bars can improve the durability and sustainability of building materials. Through the static performance test, this research analyzes the failure pattern and bearing performance of bias stainless steel reinforced concrete (SSRC) column. The influence of reinforcement ratio of longitudinal bars and eccentricity on the mechanical performance of specimens was studied. Different constitutive models of stainless steel bars were used to calculate the ultimate bearing capacity of the section of the column under eccentric compression column. Based on the experimental results, a method to modify the expression of the design specification is proposed. And, the results were compared with the test results. The results showed that the damage patterns and failure modes of SSRC columns are essentially the same as those of traditional reinforced concrete columns. The bearing capacity of SSRC columns rises with the increase in the longitudinal reinforcement ratio, and the ductility of the specimens is enhanced. The ultimate load of the specimen decreases with the rise in eccentricity but the deflection increases gradually. The strain distribution of the mid-span section of the SSRC column conforms to the plane section assumption. The bearing capacity of the specimen can be analyzed by referring to the calculation method of the specification, and some parameters in the calculation formula of the specification are modified to adapt to the design and calculation of the SSRC column.

\section{Introduction}

Reinforcement corrosion problems commonly exist in the concrete structure's durability, which lead to the unsustainability of construction projects. The investigation results show that more than $80 \%$ of concrete structures have a certain degree of durability problems or more serious steel corrosion just 5-10 years after construction [1]. How to improve the durability and sustainability of reinforced concrete structures under poor environmental conditions has become a pressing problem that requires solution. At present, the main measures taken to prevent the rapid corrosion of steel bars and improve the durability of reinforced concrete structures include [2-5] coating the surface of ordinary steel bars with antirust materials, using epoxycoated steel bars and hot-dip galvanized steel bars, controlling the quality of concrete, and using stainless steel bars. In order to fundamentally solve a series of problems caused by steel corrosion, the use of stainless steel bars is the first choice. The stainless steel reinforcement is an alloy steel and contains significant amounts of chromium in order to protect the steel against rust. It can generate a thin and smooth layer of colorless, transparent oxide film on the surface of the weak corrosive medium to protect it against environmental conditions, such as air and water. Existing research has focused on the corrosion resistance of stainless steel; however, there has been relatively little research on the mechanical performance of SSRC members. The eccentric compression member is the most fundamental and important mechanical component in a building's structure [6]; as such, research on its mechanical performance will have theoretical significance and high application value.

Currently, in China, there is a range of research on and applications for stainless steel bars and their composite materials. It mainly focuses on two aspects: one is to study its corrosion law in simulated concrete pore fluid and the other is to study its corrosion law in mortar or concrete environment, which is usually compared with carbon steel bars in the same situation by monitoring the corrosion rate. In 2006, Guoxue et al. preliminarily discussed the mechanical properties of SSRC beams, slates, and columns [7-11]. In 2007, Yongsheng et al. studied and analyzed the influence of 
the use of stainless steel bars on deflection, crack width, and ultimate bearing capacity of concrete beams and verified that the SSRC beams can meet the requirements of the maximum deflection and maximum crack width limits specified in the design of ordinary reinforced concrete structures[12]. In 2011, Huanxin et al. identified the difference between the constitutive models of stainless steel bars and ordinary steel bars [13]. In 2013, Jiawei et al. discussed the influence of use stainless steel bars on the bearing capacity of concrete beams through fatigue tests and studied the mechanical performance of SSRC beams, which included the stress-strain relationship between steel bars and concrete [10]. In 2013, Huitao conducted an experimental study on the mechanical properties of stainless steel bars, the bond properties between stainless steel bars and concrete, and the flexural properties of SSRC beams. The results showed that the strength, elongation, and cold bending property of stainless steel bars are higher than those of ordinary hot-rolled bars. The bonding performance between stainless steel bars and concrete is excellent. Under the same reinforcement condition, the bearing capacity of SSRC beam is higher than that of ordinary hot-rolled reinforced concrete beam, the failure law is consistent, and the plane section assumption is still applicable [14]. In 2014, Chen Long et al. used the potentiodynamic scanning technology and electron microscope test to study the critical chloride ion concentration of stainless steel bar and ordinary steel bar in simulated concrete pore fluid and concluded that the critical chloride ion concentration of the stainless steel bar is more than 20 times that of the ordinary steel bar and its corrosion resistance is far better than that of ordinary steel bar [15]. In 2016, Chengchang et al. proposed a preliminary calculation method for the bonding force between stainless steel bars and concrete [16], concluding that the carrying capacity of concrete beams with stainless steel bars was relatively greater. In 2018, Hailong et al. concluded that the critical value of corrosion resistance of stainless steel bars in the simulated liquid of freshly mixed concrete was more than 75 times that of carbon steel [17]. In 2018, Yi et al. studied the corrosion law of stainless steel bars and ordinary steel bars used in concrete structures. The results showed that the corrosion rate of carbon steel bars connected with stainless steel bars is significantly accelerated, and the galvanic corrosion is strengthened with the increase in corrosion time. At the same time, when two kinds of steel bars are overlapped, the galvanic corrosion is more severe [18]. In 2019, Chunyi et al. presented the bonding force formula between stainless steel bars and concrete [19].

However, overseas research on the application of stainless steel bars is a long-standing concern; as early as 1937, the Progreso Pier Bridge in Mexico used stainless steel ones to replace ordinary steel bars to improve the durability of the structure [20]. Foreign scholars' research on stainless steel bars mainly focuses on corrosion resistance. For example, in 1985, Zoob et al. carried out the corrosion resistance test on 304 stainless steel bars. The research showed that the allowable chloride content of stainless steel bars buried in concrete is 7-10 times that of ordinary steel bars in the same environment and there is no obvious corrosion of stainless steel bars. In 1988, Flint et al. buried one end of 316 stainless steel bars and carbon steel bars in concrete and exposed the other end to sea water. The experimental results showed that the local erosion of stainless steel bars only occurred in the immersion section of sea water, the stainless steel bars wrapped in concrete remained intact, and the overall strength was not affected. However, the corrosion of carbon steel bars was significant and the strength was seriously reduced [21, 22]. In 1995, McDonld and others conducted the same experimental study on SSRC members and the results showed that the corrosion resistance of SSRC members was better than that of ordinary reinforced concrete members [23]. In 1998, Bertolini et al. conducted corrosion tests on SSRC members in high $\mathrm{pH}$ value and high chloride environment and found that the corrosion resistance of stainless steel reinforcement is extremely excellent. It can still remain passive in high $\mathrm{pH}$ value and high chloride environment [24]. In 2002, Abreu et al. used sodium chloride solution to simulate concrete pore fluid and used the EIS method and ZRA method to study galvanic corrosion behavior of the stainless steel bar and carbon steel bar. The results show that if the carbon steel bar and stainless steel bar are connected in simulated pore fluid, the probability of galvanic corrosion is small [25]. Castro (2003) conducted tests on the mechanical properties and corrosion properties of the austenitic stainless steel rebar under both hot-rolled and cold-rolled conditions [26]. Blanco et al. experimentally compared the corrosion behavior of two traditional austenitic steels and a dual-phase stainless steel with that of low nickel austenitic steel [27]. In 2010, Milan Kouril et al. studied the corrosion resistance of stainless steel bars by the electrochemical test, and the results showed that the critical chloride concentration of stainless steel bars in concrete structure depends not only on the chemical composition of stainless steel and the $\mathrm{pH}$ level of concrete pore fluid but also on the surface state of steel. Stainless steel bars with smooth surface have good corrosion resistance, while stainless steel bars with rough surface have weak resistance to chloride ion [28]. In 2013, Hansson et al. used the linear polarization method to compare the corrosion performance of the stainless steel bar and carbon steel bar in concrete environment with the same chloride concentration. The results showed that the corrosion of ordinary carbon steel bar occurred within two weeks, while the stainless steel bar began to rust after 139 weeks. The use of stainless steel bars has a significant effect on improving the service life of concrete structures [29]. And, Gastaldi and Bertolini tested the chloride-induced corrosion resistance of low nickel bidirectional stainless steel threaded bars in different temperature ranges and traditional austenitic stainless steel threaded bars [30]. In recent years, foreign studies on the mechanical properties of stainless steel have gradually increased. In 2015, Mdina et al. carried out a series of experimental studies on the structural properties of three kinds of stainless steel bars (austenitic AISI304, bidirectional AISI2304, and new bidirectional AISI2001) at reinforcement, section, and structural member levels, respectively [31]. In 2016, Gardner et al. conducted 164 heating tests on four kinds of stainless steel bars (1.4307[304Ln], 1.4311 
[304Ln], 1.4162[LDX2101], and 1.4362[2304]) under hightemperature conditions [32]. In 2019, Yibu et al. conducted an experimental study on the strength of 59 stainless steel welding sections using through traditional welding and laser welding [33]. In 2019, Bemfica et al. studied axial torsional fatigue and cyclic deformation behavior of 304L stainless steel bars at room temperature [34].

Stainless steel bars have high strength, high flexural strength ratio, high fatigue life, high impact toughness, and other properties. The main problem of the current application of stainless steel reinforcement is the high price, which affects the initial cost of engineering construction. But, generally, the stainless steel reinforcement can only be used in the key parts of the actual project, so the proportion of stainless steel reinforcement in the whole project cost is very small and some other characteristics of stainless steel reinforcement also make its life cycle cost much lower than that of carbon steel [35]. Compared with ordinary steel bars, first of all, the application of stainless steel bars can reduce the thickness of concrete and the number of steel bars. Secondly, the transportation, processing, and installation of stainless steel bars have no special requirements, and the construction cost is $25 \%$ lower than that of epoxy-coated carbon steel bars. Thirdly, stainless steel reinforced concrete buildings require little or no maintenance which can reduce maintenance and inspection costs, thereby reducing the social cost of maintenance disrupting operations. The Federal Highway Administration (FHWA) conducted a cost analysis of three bridges built in Illinois with different rustproofing methods. The results showed that the initial cost of the bridge with stainless steel reinforcement increased by $16 \%$, but it took about six times as long to crack, resulting in a significant reduction in maintenance costs [36]. $\mathrm{V}$ al et al. put forward a kind of time-varying probability model to predict the expected cost of repair and replacement, and then, the model was used to calculate different exposures of reinforced concrete structures in the marine environment under the conditions of life cycle cost. The results showed that although the price of stainless steel was six to nine times that of carbon steel, the use of stainless steel bars was justified on a life cycle cost basis [37]. Frank $\mathrm{N}$. Smith analyzed the serious corrosion problems during the service of the Oland Bridge in Sweden, pointed out that if the bridge were constructed with stainless steel bars, the construction cost would only increase by $8 \%$, but the 100 -year life could be achieved with very little maintenance [38]. Cope et al. evaluated the superiority of stainless steel over conventional steel in terms of both long-term usage costs and user costs with the data from one Midwestern state in the United States, using Monte Carlo simulation methods for most of the analyzed scenarios, which proved that in the case of uncertainty, using stainless steel as the bridge reinforcement materials is more cost-effective than conventional steel [39]. Younis et al. conducted a life cycle cost analysis of high-rise buildings based on a 100-year study period and showed that the proposed combination using stainless steel bars had a life cycle cost (LCC) approximately 50\% lower than the conventional combination (i.e., concrete containing fresh water, natural aggregate, and black steel) [40].
Although there has been much progress in the study of stainless steel bars, most has concentrated on the performance of the stainless steel material itself, such as stainless steel basic mechanical performance, weldability, and corrosion resistance. However, there has been relatively little research on the mechanical properties of concrete structural members containing stainless steel bars. When stainless steel bars are used in concrete compression members, whether the stainless steel bars and concrete materials can fully live up to their strengths needs to be verified through rigorous testing. In view of this, this paper will consider the SSRC columns as the research participants. Through testing, theoretical analysis, numerical simulation, and other technical methods, the mechanical performance of SSRC columns will be studied.

\section{Experimental Design}

2.1. Specimen. In order to conduct the study, eight SSRC eccentric compression columns were designed and constructed. The section determination of each specimen was $250 \mathrm{~mm} \times 150 \mathrm{~mm}$, with a height of $1000 \mathrm{~mm}$. The form of symmetrical reinforcement was adopted, and the concrete cover thickness was $25 \mathrm{~mm}$. The model of stainless steel bar used along the longitudinal direction of the specimen was 2304. The specific dimensions and reinforcement layout of the specimens are shown in Figure 1.

At the same time, six $150 \mathrm{~mm} \times 150 \mathrm{~mm} \times 150 \mathrm{~mm}$ standard concrete companion specimens were poured for each concrete bias specimen. These were used for testing the concrete strength of the specimens.

2.2. Experimental Methods. The design parameters of the specimens are listed in Table 1 . The test was carried out on a WHY $-5000 \mathrm{kN}$ hydraulic pressure machine. In order to measure the strain on the concrete, six strain gauges were pasted equidistant on the middle section of the specimen. Three strain gauges were uniformly pasted on the surface of each longitudinal stainless steel bar of the specimen to measure the strain on the longitudinal steel bars. On the middle section of the bottom surface of the specimen, equidistant to each other, 5 displacement meters were placed to measure the deflection of the specimens. Figures 2 and 3 show the loading diagram and strain gauge distribution, respectively. Crack development, concrete strain, reinforcement strain, lateral displacement, and other test phenomena were observed and recorded during the test.

\subsection{Mechanical Properties of Concrete and Reinforcement.} In this experiment, 2304 stainless steel bars were used. Stainless steel specimens with diameters of $12 \mathrm{~mm}, 16 \mathrm{~mm}$, and $25 \mathrm{~mm}$ were selected for tensile testing. The test results and the mechanical indexes of stainless steel bars are shown in Figure 4 and 5 and Table 2.

The design strength of the concrete specimen is C45, and the measured strength of the concrete test blocks is shown in Table 3 . The axial compressive strength of concrete is calculated using formula (1), according to the 


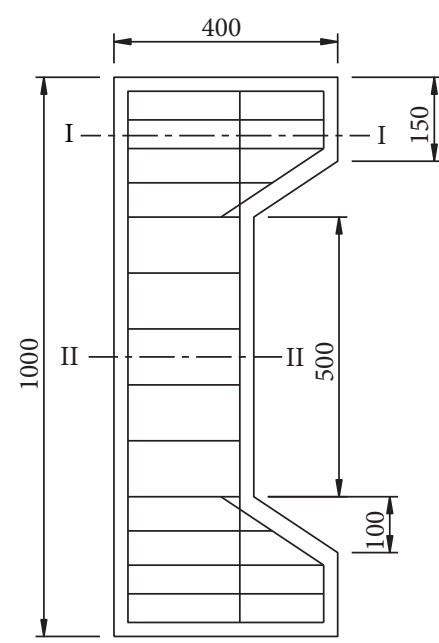

(a)

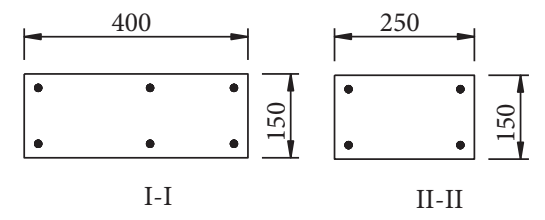

(b)

(c)

Figure 1: Schematic of specimen dimensions and reinforcement (mm).

TABLE 1: Specimen design parameters.

\begin{tabular}{|c|c|c|c|c|c|}
\hline $\begin{array}{l}\text { Specimen } \\
\text { number }\end{array}$ & Strength grade of concrete & $\begin{array}{c}\text { Sectional } \\
\text { dimension }\left(\mathrm{mm}^{2}\right)\end{array}$ & $\begin{array}{c}\text { Initial eccentricity, } \\
e_{0}(\mathrm{~mm})\end{array}$ & $\begin{array}{c}\text { Longitudinal } \\
\text { reinforcement } \\
\text { diameter, } d(\mathrm{~mm})\end{array}$ & $\begin{array}{l}\text { Hoop reinforcement } \\
\quad \text { form, } d(\mathrm{~mm})\end{array}$ \\
\hline A-D1 & $\mathrm{C} 45$ & $250 \times 150$ & 200 & 12 & 8@125 \\
\hline A-D4 & $\mathrm{C} 45$ & $250 \times 150$ & 50 & 12 & 8@125 \\
\hline B-D1 & $\mathrm{C} 45$ & $250 \times 150$ & 200 & 16 & 8@125 \\
\hline B-D2 & $\mathrm{C} 45$ & $250 \times 150$ & 150 & 16 & 8@125 \\
\hline B-D3 & $\mathrm{C} 45$ & $250 \times 150$ & 100 & 16 & 8@125 \\
\hline B-D4 & $\mathrm{C} 45$ & $250 \times 150$ & 50 & 16 & 8@125 \\
\hline C-D1 & $\mathrm{C} 45$ & $250 \times 150$ & 200 & 25 & 8@125 \\
\hline $\mathrm{C}-\mathrm{D} 4$ & $\mathrm{C} 45$ & $250 \times 150$ & 50 & 25 & 8@125 \\
\hline
\end{tabular}

Note: letters A, B, and C represent the longitudinal stainless steel bars with diameters of $12 \mathrm{~mm}, 16 \mathrm{~mm}$, and $25 \mathrm{~mm}$ respectively. D1, D2, D3, and D4 represent the initial eccentricity of $200 \mathrm{~mm}, 150 \mathrm{~mm}, 100 \mathrm{~mm}$, and $50 \mathrm{~mm}$, respectively, when the specimen is pressed.

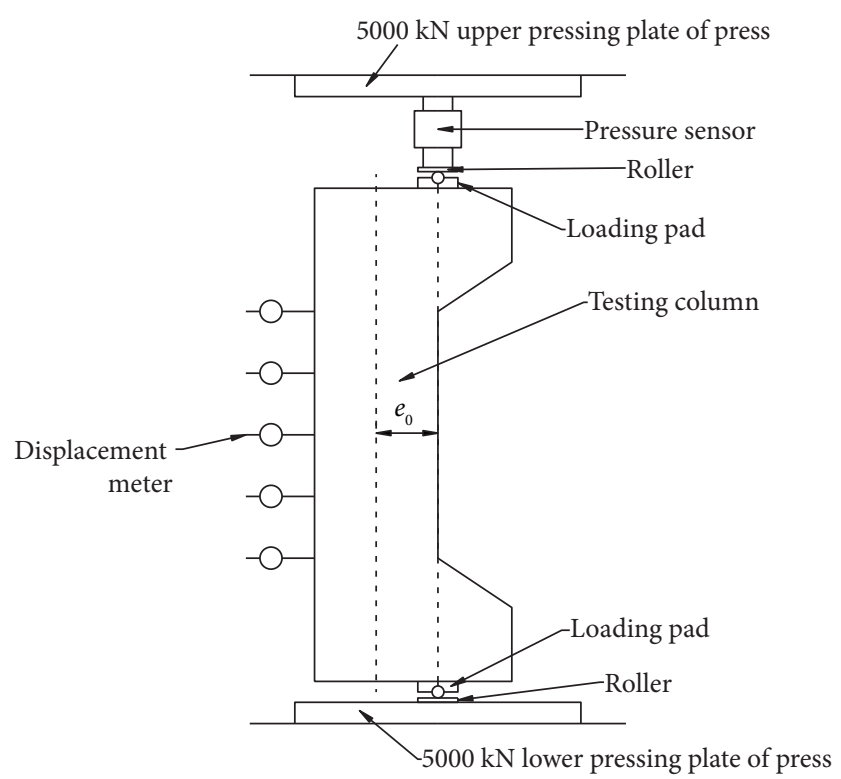

Figure 2: Experimental loading diagram. 


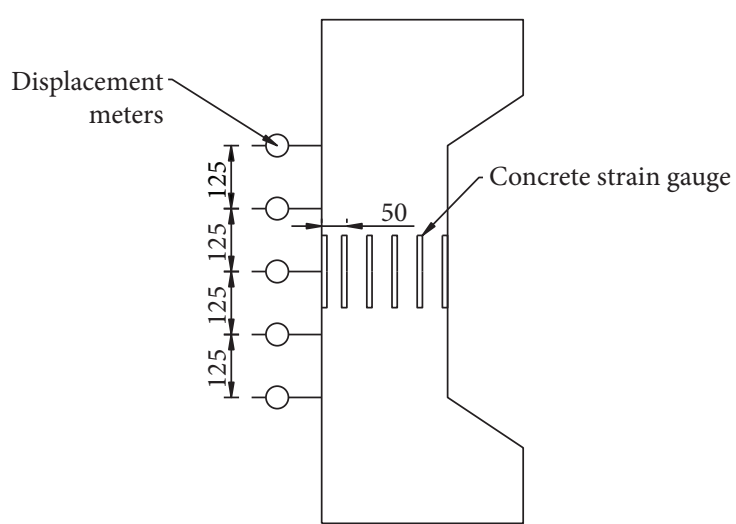

FIgURE 3: Distribution of the strain gauge $(\mathrm{mm})$.

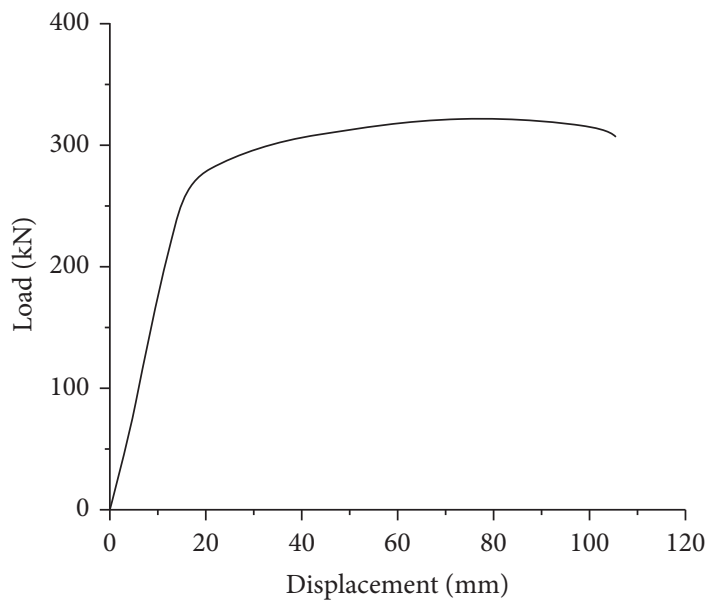

FIgURE 4: Load-displacement curve of stainless steel bars.

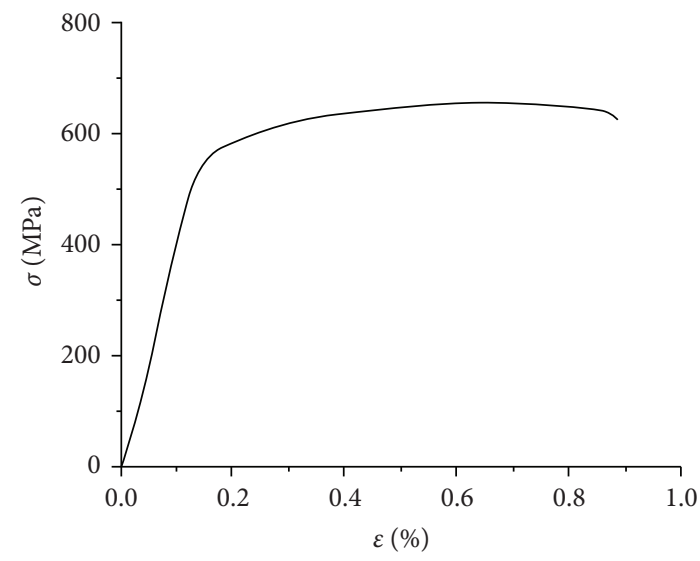

FIgURE 5: Stress-strain curve of stainless steel bars.

Code for Design of Concrete Structures (GB50010-2010). Considering that all the specimens are manufactured and tested under laboratory conditions, the reduction factor of 0.88 can be ignored, so the actual strength of the concrete can be calculated using formula (2). Calculations for the mechanical properties of the concrete are shown in Table 3.

$$
\begin{aligned}
f_{c k} & =0.88 \times 0.76 f_{c u, k}, \\
f_{k} & =00.76 f_{c u, k} .
\end{aligned}
$$

\section{Results and Discussion}

3.1. Experiment Phenomena and Failure Modes. The experiments can be divided into two conditions: large eccentric compression, for which the initial eccentricities are $150 \mathrm{~mm}$ and $200 \mathrm{~mm}$, and small eccentric compression, which includes the initial eccentricities of $50 \mathrm{~mm}$ and $100 \mathrm{~mm}$. Specimens with D1/D2 in the specimen number are those with large eccentric compression, and the failure modes of specimens with large eccentric compression are essentially the same. When the load increased to $15-25 \%$ of the peak load, 2-4 horizontal cracks formed in the tensile zone of the SSRC columns. At the point of these cracks in the tensile zone, the strain on the stainless steel bars and the mid-span deflection of the SSRC columns greatly increased. As the load continued to increase, the cracks were more or less equally spaced, forming several major cracks. With further increase in the load, the width of the cracks increased, gradually extending to the compression zone, and the height 
TABLE 2: Mechanical indexes of stainless steels.

\begin{tabular}{lcccc}
\hline Diameter $(d / \mathrm{mm})$ & Tensile strength $(\mathrm{MPa})$ & Yield strength $(\mathrm{MPa})$ & Elastic modulus $\left(10^{5} \mathrm{MPa}\right)$ & Elongation $(\%)$ \\
\hline 12 & 885.3 & 677.5 & 1.56 & 33.00 \\
16 & 795.3 & 565.8 & 1.56 & 36.39 \\
25 & 768.7 & 572.7 & 1.40 & 34.13 \\
\hline
\end{tabular}

TABLE 3: Mechanical properties of concrete.

\begin{tabular}{lcccc}
\hline Specimen number & $f_{c u}(\mathrm{MPa})$ & $f_{c}(\mathrm{MPa})$ & Specimen number & $f_{c u}(\mathrm{MPa})$ \\
\hline A-D1 & 43.47 & 33.04 & B-D3 & 42.44 \\
A-D4 & 42.64 & 31.65 & B-D4 & 46.00 \\
B-D1 & 45.20 & 34.20 & C-D1 & 45.33 \\
B-D2 & 44.93 & 34.15 & C-D4 & 45.60 \\
\hline
\end{tabular}

of the compression zone of the SSRC columns decreased. When the load reached $80-90 \%$ of the peak load, the stainless steel bars in the tensile zone were close to yield: the strain on the stainless steel bars rapidly increased, the height of the compression zone of the specimen decreased, the compressive strain on the concrete in the compression zone of the concrete columns and the stainless steel bars increased, and longitudinal cracks appeared. As the load continued to increase, the bearing capacity of the specimens decreased abruptly, the strain on the concrete in the compression zone reached the ultimate compressive strain state, and the specimens were crushed. On the destruction of the specimens, the concrete in the compression area was crushed and, while the stainless steel bars in the compression area did not yield, the stainless steel bars in the tensile area did. The lateral deflection of the specimens was large, and there were characteristics of ductile failure [41].

Specimens with D3/D4 in the specimen number are the specimens with small eccentric compression, and the failure modes of all specimens with small eccentric compression are essentially comparable. When the load increased to $25-40 \%$ of the peak load, several small cracks appeared in the tensile zone and the width of the cracks and their extension to the compression zone were not obvious. No main cracks formed, and the strain at the edge of the compression zone of the specimens increased rapidly. With an increase in the load, the strain on the stainless steel bars and concrete in the compression area of the specimens increased significantly and the cracks in the tensile area extended and developed slowly. When approaching failure conditions, longitudinal cracks appeared in the concrete in the compression zone. The destruction was sudden, without any visible symptoms, and the crushing area was large. When the specimens were destroyed, the reinforcement on the side closest to the loading point yielded, while the reinforcement on the side furthest from the loading point did not. The lateral deflection of the specimens was small, and the specimens showed certain characteristics of brittleness [41]. The failure mode of the specimens is shown in Figure 6.

3.2. Load-Deflection Curves. The load-deflection curves of each specimen are shown in Figure 7. It can be seen in the graphs that the load-deflection curve of SSRC eccentric compression columns is more or less divided into three stages. First is the linear elastic stage: the bearing capacity of the SSRC column is still small, the specimen has not cracked, and the deflection is also small. At this point, the relationship of load-deflection is approximately linear. The second stage is the nonlinear ascending stage: with the increase in load, both the amount and width of the cracks in the tensile zone of the specimen increase and the cracks further extend to the compression zone. The plastic characteristics of the specimen become increasingly obvious. At this stage, there is a nonlinear relationship between load and deflection and, with an increase in load, the relationship becomes increasingly obvious and the slope becomes smaller, indicating a continuous decline in specimen stiffness. The third stage is the descending stage: after the peak load exceeds, the deflection of the specimen increases and the load decreases [42]. The descending section of the large eccentric compression SSRC columns is relatively gentle, and the ductility of the specimens is good. In order to protect the instrument, the displacement gauge for some specimens was removed at $80 \%$ of the peak load, so the descending section is not presented in the graphs.

3.3. Influencing Factor Analysis. In order to study the stress of stainless steel bars in concrete eccentric pressure columns, the load-reinforcement strain curve of each specimen was drawn, as shown in Figure 8. As can be seen in Figure 8, the load-strain curve of the specimens with large eccentricity failure (A-D1, B-D1, B-D2, and C-D1) can be more or less divided into the following three stages: the elastic stage, where the strain and load of the tensile stainless steel bars show an approximate linear relationship; the nonlinear stage, where the height of the compression zone decreases gradually with an increase in load, the stress is redistributed, and the load-strain curve of the stainless steel bars deviated from the original linear relationship and began to show nonlinearity; and, finally, the approximate level development stage, where the stainless steel bar strain increased and the bars were close to yield. Making full use of tensile area and the compression area, the stainless steel bars did not yield. In the specimens with small eccentric failure (A-D4, B-D3, B-D4, and C-D4), the load-strain curve of the compressive steel bar is essentially the same as that of the 


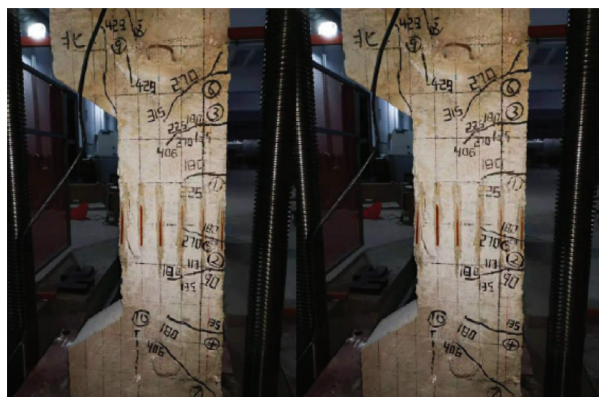

(a)

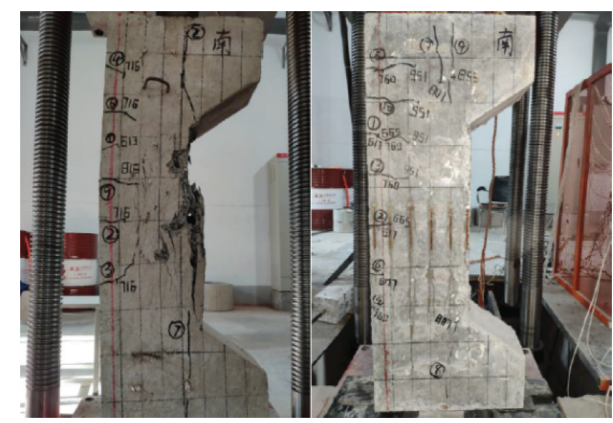

(b)

FIgURE 6: Failure mode of the specimen. (a) Large eccentric compression failure. (b) Small eccentric compression failure.

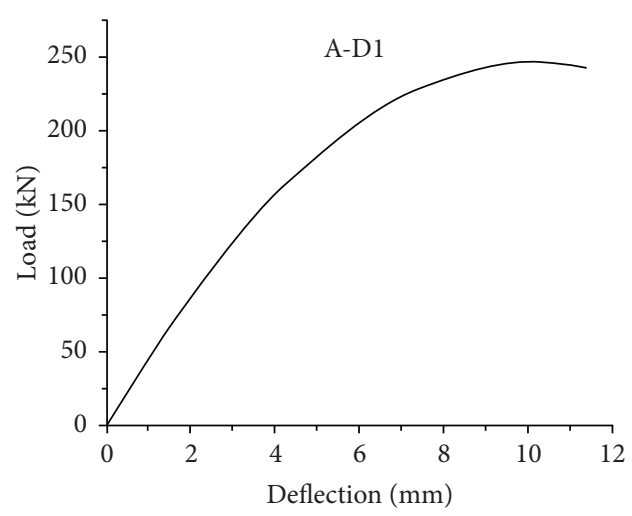

(a)

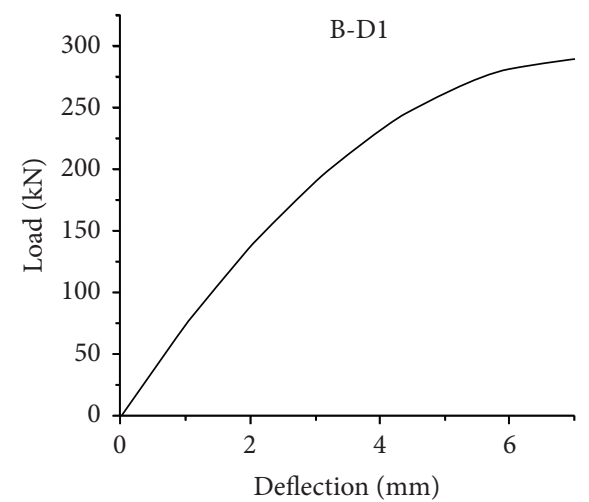

(c)

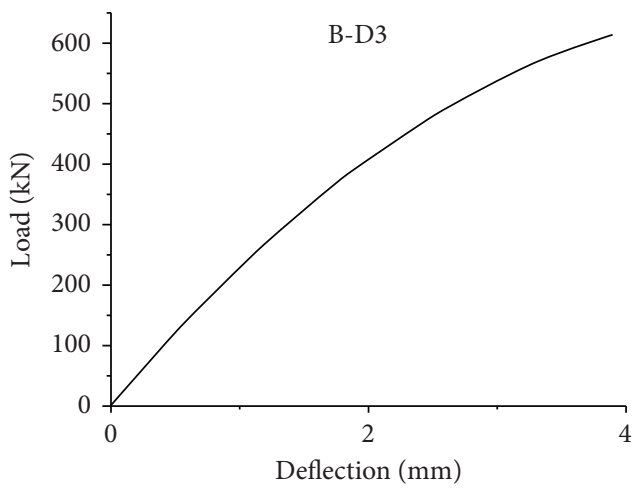

(e)

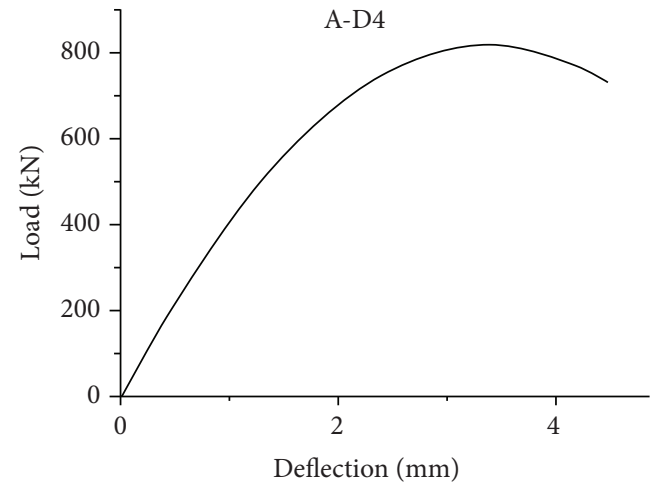

(b)

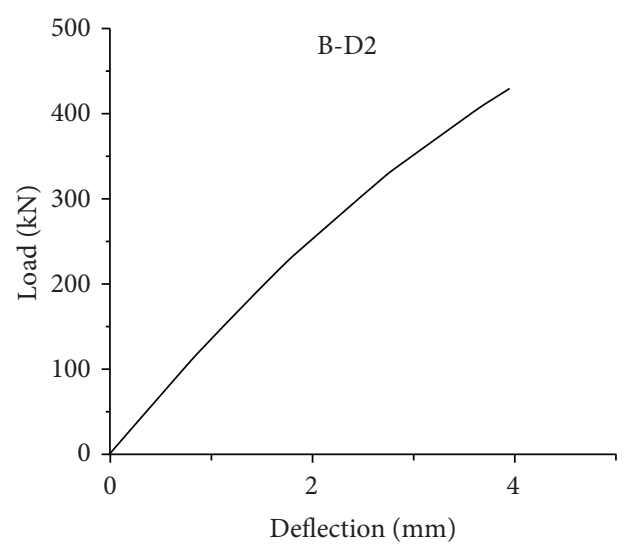

(d)

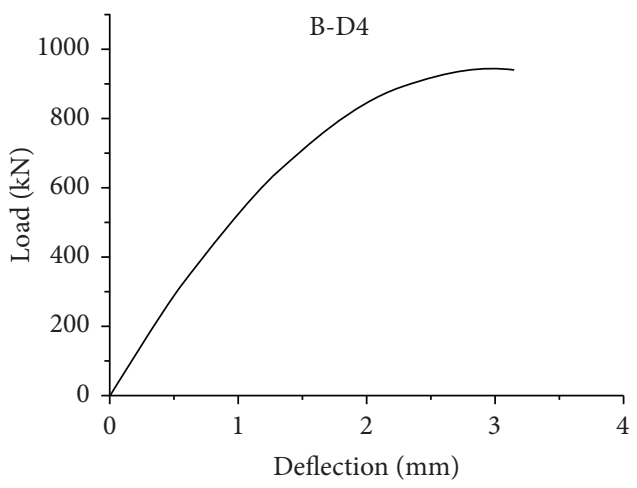

(f)

Figure 7: Continued 


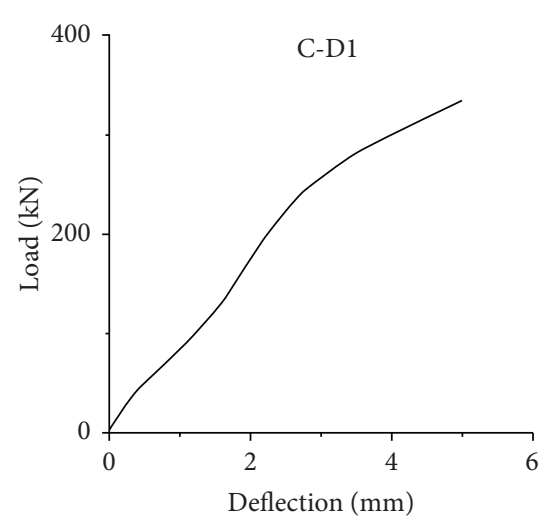

(g)

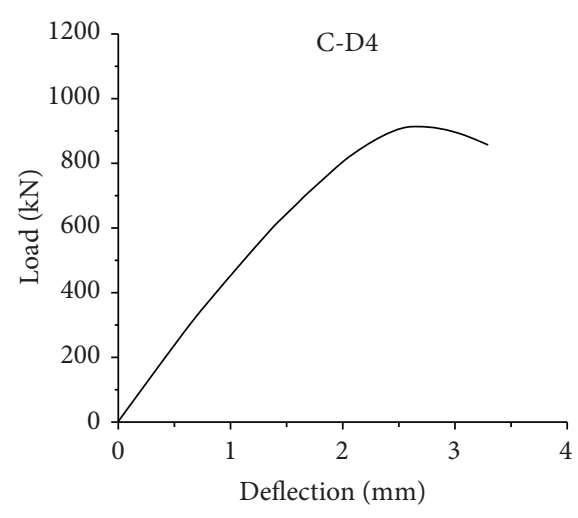

(h)

Figure 7: Load-deflection curve of the specimens.

tensile stainless steel bar in large bias pressure. The stainless steel bars in the compression zone ultimately yielded, meaning that the stainless steel bars in the compression zone can be fully utilized. The strain of the stainless steel bars in the tensile area is small, unyielding, and not fully utilized. This is synonymous with the small bias of ordinary concrete columns. When the eccentricity of the tensile stainless steel bars is $50 \mathrm{~mm}$, the stainless steel bars furthest away from the loading point also appear to be under compression [42]. This is because the initial eccentricity is too small, so the steel bars in the tensile area of the specimen appear to be under compression, as shown in graphs (f) and (h) in Figure 8.

The load-deflection curves of different reinforcement ratios of longitudinal steels with the same eccentricity are displayed in Figure 9. It can be seen from the graphs that the ratio of longitudinal reinforcement has a significant influence on the bearing capacity and deflection of SSRC columns. When the initial eccentricity is $200 \mathrm{~mm}$ meaning the specimen is under large eccentricity compression, with the same load condition, the smaller the reinforcement ratio, the greater the deflection, and the flatter the load-deflection curve. When the initial eccentricity is $50 \mathrm{~mm}$, in the case of small eccentricity compression, the change in the reinforcement ratio of longitudinal stainless steel has little effect on the deflection of the specimen.

Eccentricity has a significant effect on the load and deflection of concrete columns. Under the same conditions, the deflection corresponding to the ultimate load of the SSRC column rises with the increase in eccentricity, the load-deflection curves are gentler, and the bearing capacity of the specimens decreases. The comparison of the influence of eccentricity on the load-deflection curve of SSRC columns is shown in Figure 10 [43].

3.4. Main Results. The main results of this research are shown in Table 4. It can be seen from the table that, under the condition of large eccentricity pressure, the stainless steel bars on the tensile side have yielded, while the stainless steel bars on the compression side mostly have not. This phenomenon is different from that of ordinary carbon-reinforced concrete specimens. In the case of small eccentricity pressure, the steel on the compression side has mostly yielded, while the stainless steel bars on the side furthest from the loading point have not, which is consistent with that of ordinary carbon-reinforced concrete specimens [44-48]. Stainless steel bars can play a more beneficial role in concrete columns, but there are some disparities to ordinary reinforced concrete columns. As such, the calculation of SSRC columns cannot replicate the standard results of ordinary reinforced concrete columns.

\section{Carrying Capacity Calculation}

4.1. Verification of Plane Section Assumption. Figure 11 shows the distribution of strain in the mid-span section along the height under various loads. It can be seen that the strain distribution along the height of the column in the mid-span section of the specimen is uniform and mostly linear, which meets the requirements of plane section assumption [49].

4.2. Calculation of Ultimate Bearing Capacity. The mechanical properties of stainless steel bars are shown in Table 5.

The constitutive model of stainless steel adopts the Rasmussen model and the constitutive model of steel according to China's current standards [50].

The mathematical expression of the Rasmussen model is

$$
\varepsilon= \begin{cases}\frac{\sigma_{s}}{E_{0}}+\varepsilon_{p y}\left(\frac{\sigma_{s}}{\sigma_{0.2}}\right)^{n}, & \varepsilon \leq \varepsilon_{0.2}, \\ \frac{\sigma_{s}-\sigma_{0.2}}{E_{0.2}}+\varepsilon_{u}\left(\frac{\sigma_{m}-\sigma_{0.2}}{\sigma_{u}-\sigma_{0.2}}\right)^{m}, & \varepsilon_{0.2}<\varepsilon \leq \varepsilon_{u},\end{cases}
$$

where $E_{0}$ is the initial elastic modulus; $\varepsilon_{p y}$ is the residual strain, and $\varepsilon_{p y}=0.002 ; n=\ln 20 / \ln \left(\sigma_{0.2} / \sigma_{0.01}\right)$, and $\sigma_{0.01}$ is the point corresponding to the $0.01 \%$ residual strain of the steel bar; $E_{0.2}$ is the slope of the tangent line at the nominal yield point; $m=1+3.5 \sigma_{0.2} / \sigma_{u}$; and $\varepsilon_{u}=1-\sigma_{0.2} / \sigma_{u}$.

The mathematical expression of the steel bar constitutive model in China's current code is 


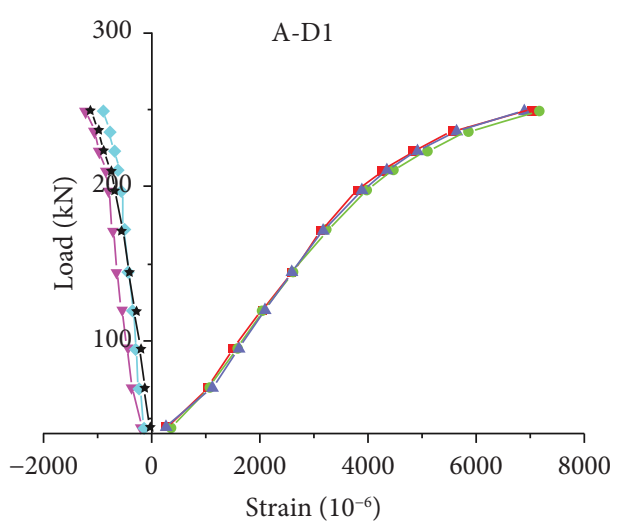

- - Tensile zone bar $1-\nabla-$ Compressive zone bar 1

- - Tensile zone bar $2-\downarrow-$ Compressive zone bar 2

-₫- Tensile zone bar $3 \quad-\star-$ Compressive zone bar 3

(a)

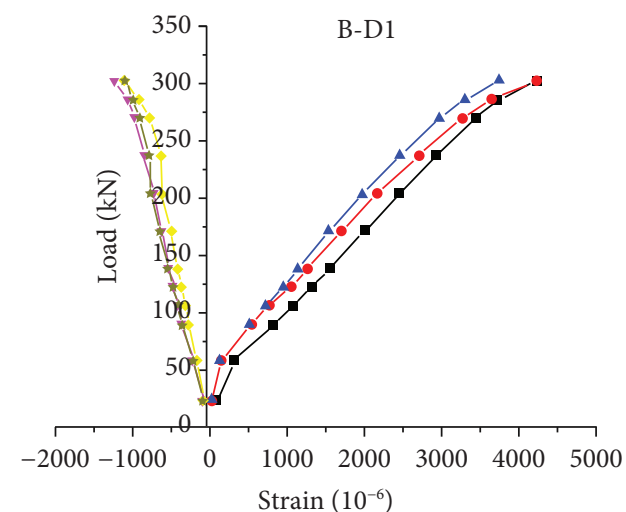

- - - Tensile zone bar $1-\nabla-$ Compressive zone bar 1

- - Tensile zone bar $2 \quad-\downarrow-$ Compressive zone bar 2

-₫- Tensile zone bar $3 \quad-\star-$ Compressive zone bar 3

(c)

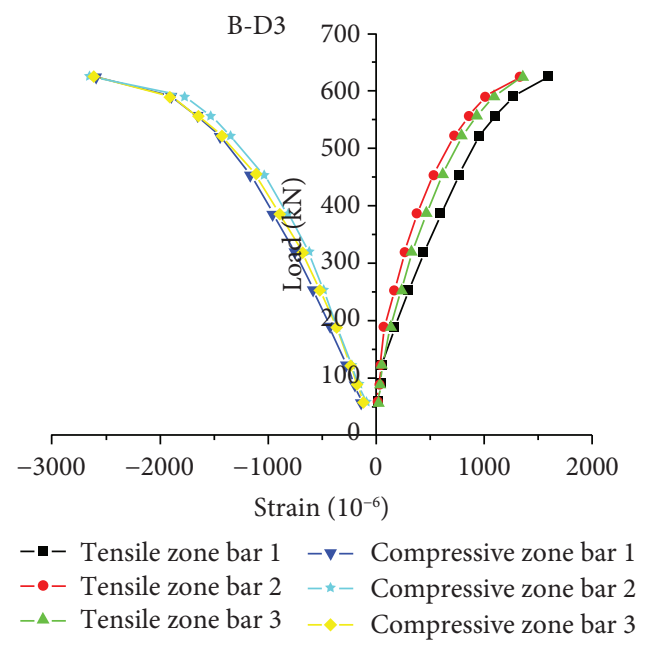

(e)

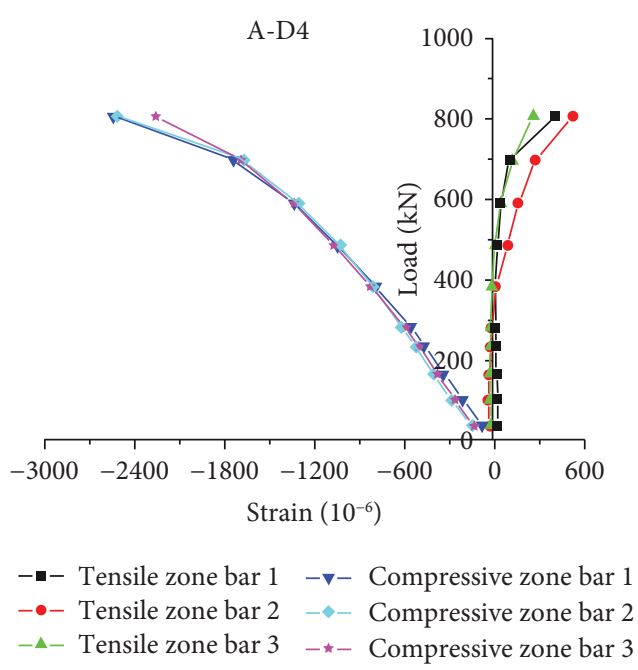

(b)

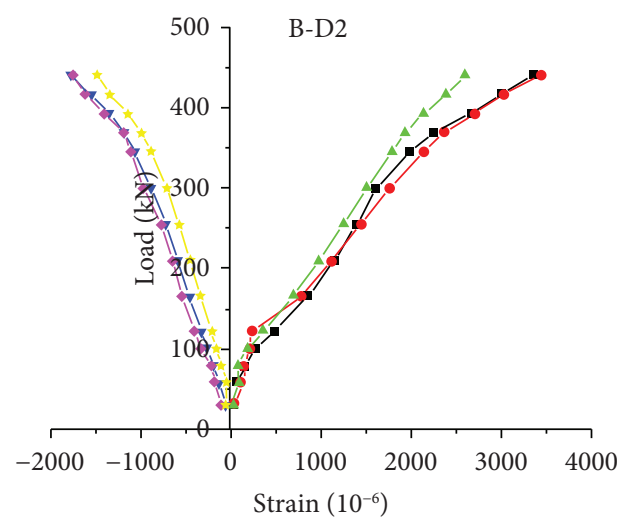

-q- Tensile zone bar $1 \quad-\mathbf{v}-$ Compressive zone bar 1

- - Tensile zone bar 2 - - Compressive zone bar 2

$-\Delta-$ Tensile zone bar $3 \quad-*-$ Compressive zone bar 3

(d)

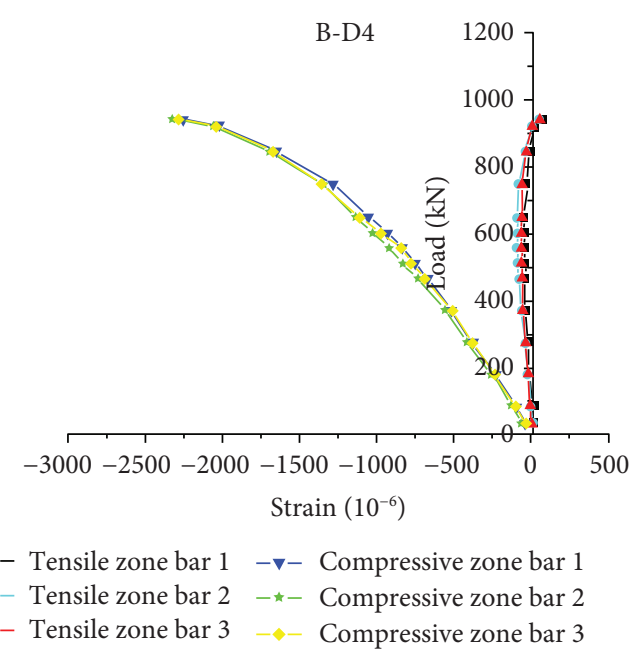

(f)

Figure 8: Continued. 


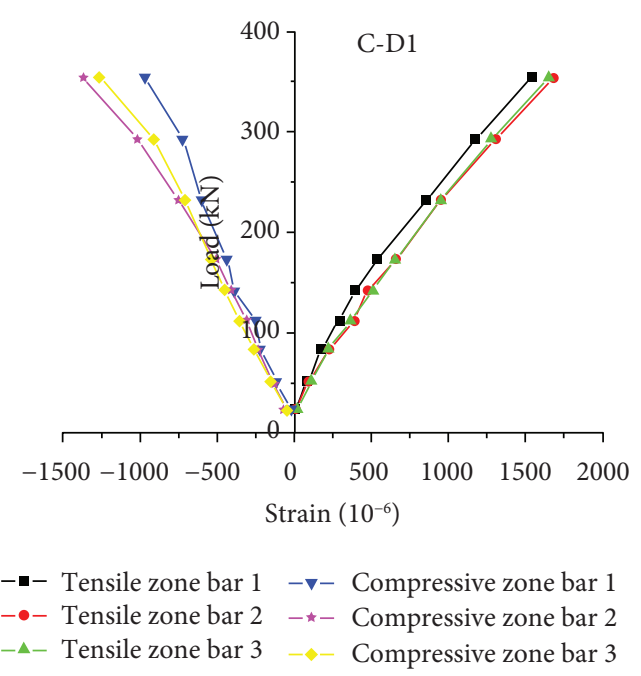

(g)

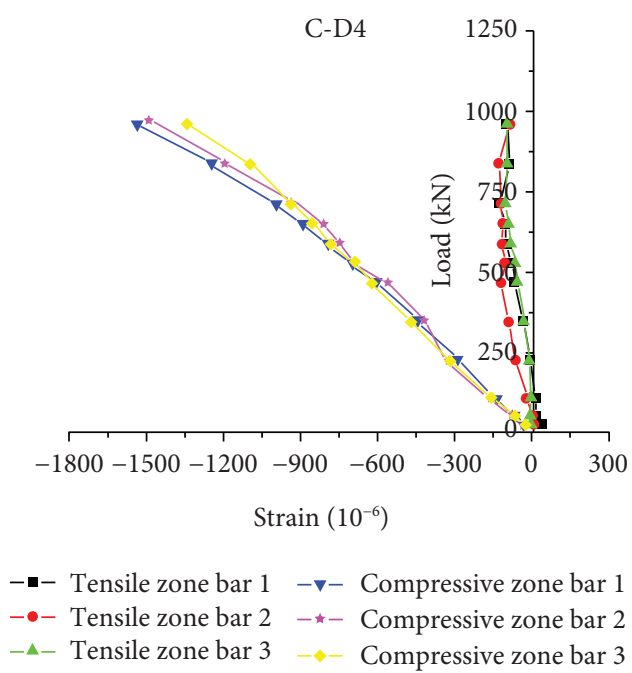

(h)

FIGURE 8: Load-longitudinal reinforcement strain curve of the specimen.

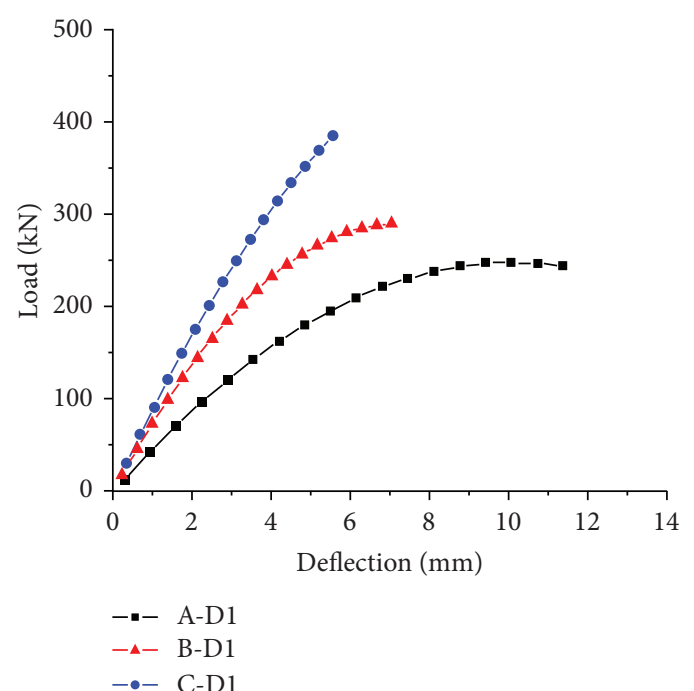

(a)

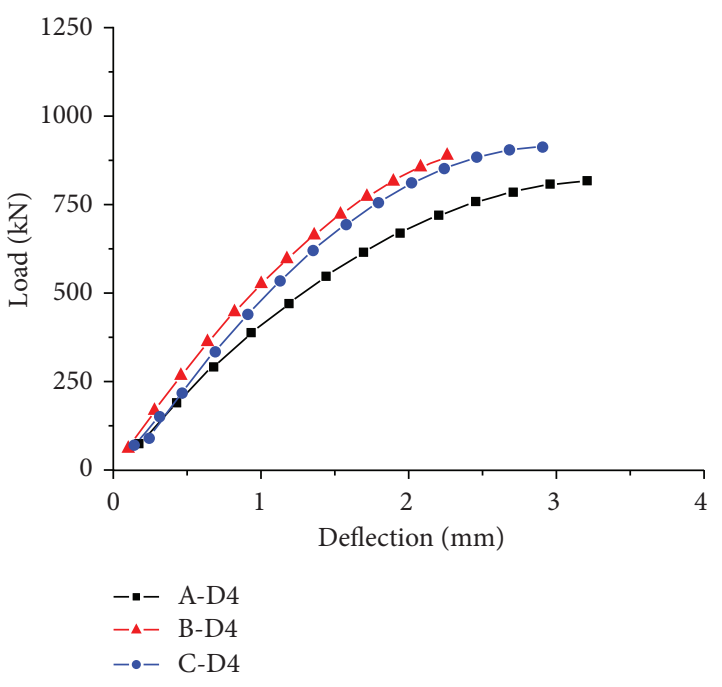

(b)

FIGURE 9: Influence of longitudinal reinforcement ratio on the load-deflection curve.

$$
\sigma= \begin{cases}E_{0} \varepsilon, & \varepsilon \leq \varepsilon_{0.2}, \\ \sigma_{0.2}+k\left(\varepsilon-\varepsilon_{0.2}\right), & \varepsilon_{0.2}<\varepsilon \leq \varepsilon_{u}, \\ 0, & \varepsilon>\varepsilon_{u},\end{cases}
$$

where $\sigma$ is the steel bar stress, $E_{0}$ is the initial elastic modulus of the steel, $\varepsilon$ is the steel bar strain, $\sigma_{0.2}$ is the nominal yield stress of the stainless steel bar, $\varepsilon_{0.2}$ is the strain corresponding to the nominal yield stress of the steel bar, $\varepsilon_{u}$ is the peak strain corresponding to the ultimate strength of the steel, and $k$ is the slope of the hardened section of the steels, where $k=\left(\sigma_{u}-\sigma_{0.2}\right) /\left(\varepsilon_{u}-\varepsilon_{0.2}\right)$.

According to the force balance of the damaged section in the stainless steel reinforcement eccentric compression members and the momentary balance of the center point in the tension steel bars, the calculation formula for the bearing capacity of the rectangular section of the SSRC eccentric compression columns can be obtained [43]:

$$
\left\{\begin{array}{l}
N=f_{c} b x+\sigma_{s}^{\prime} A_{s}^{\prime}-\sigma_{s} A_{s}, \\
N e=f_{c} b x\left(h_{0}-\frac{x}{2}\right)+\sigma_{s}^{\prime} A_{s}^{\prime}\left(h_{0}-a_{s}^{\prime}\right) .
\end{array}\right.
$$

The theoretical value of the ultimate bearing capacity of stainless steel bar concrete eccentric pressure specimens under two constitutive models can also be obtained, as demonstrated in Table 6.

4.3. Comparative Analyses. In this experiment, eight stainless steel bar eccentric concrete column bearing capacity 


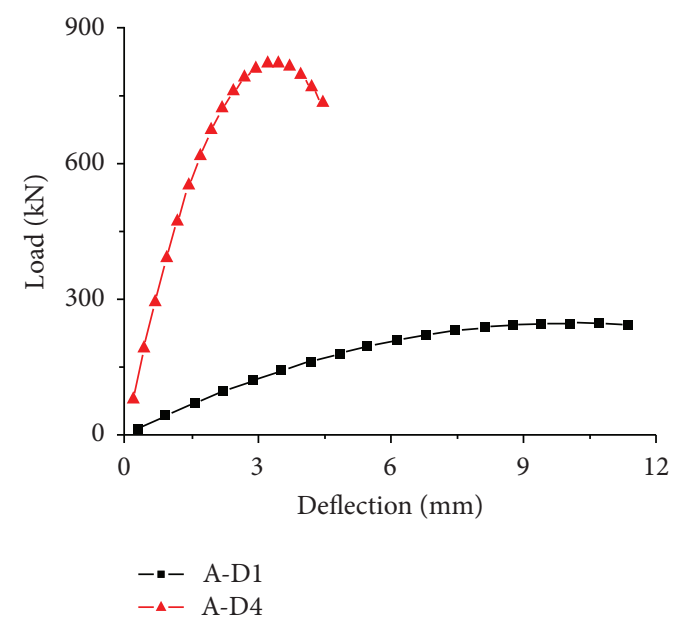

(a)

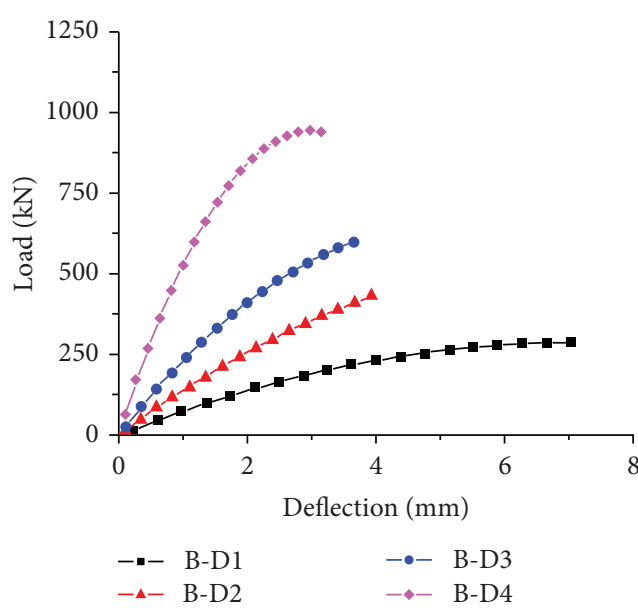

(b)

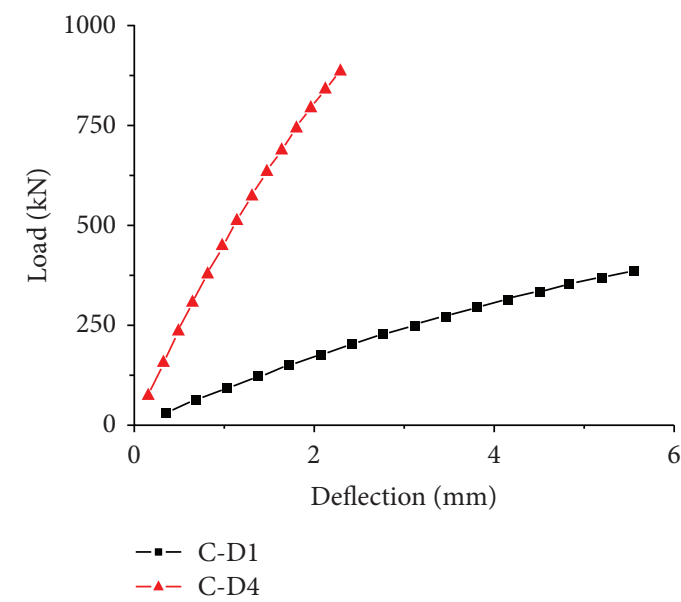

(c)

Figure 10: Comparison of the influence of eccentricity on the load-deflection curve.

TABLE 4: Main test data.

\begin{tabular}{|c|c|c|c|c|c|}
\hline Specimen number & $e_{0} / h_{0}$ & $N_{u}(\mathrm{kN})$ & $\varepsilon_{s}^{\prime}\left(10^{-6}\right)$ & $\varepsilon_{s}\left(10^{-6}\right)$ & Failure pattern \\
\hline A-D1 & 0.913 & 242.2 & -1195.05 & 6152.23 & Large eccentricity \\
\hline A-D4 & 0.228 & 807.2 & -2422.90 & 384.45 & Small eccentricity \\
\hline B-D1 & 0.922 & 302.1 & -1251.09 & 4183.15 & Large eccentricity \\
\hline B-D2 & 0.691 & 440.5 & -1850.98 & 2983.35 & Large eccentricity \\
\hline B-D3 & 0.461 & 625.4 & -2657.56 & 1707.61 & Small eccentricity \\
\hline B-D4 & 0.230 & 952.0 & -2775.89 & 279.73 & Small eccentricity \\
\hline C-D1 & 0.941 & 353.5 & -1166.36 & 1724.76 & Large eccentricity \\
\hline $\mathrm{C}-\mathrm{D} 4$ & 0.235 & 1032.0 & -1877.59 & -16.99 & Small eccentricity \\
\hline
\end{tabular}

Note: $N_{u}$ represents the maximum bearing load of the specimen, and $\varepsilon_{s}^{\prime}$ and $\varepsilon_{s}$ represent the strain of compression stainless steel and tension stainless steel bars, respectively, when the threshold load is reached. In this table, negative values represent compression and positive values represent tension.

tests were carried out and the experimental values were compared with the calculated theoretical values. The comparison results are shown in Table 6. Through comparative analysis, it can be seen that the ultimate bearing capacity of the stainless steel bar concrete column's eccentric loadbearing capacity failure specimen is similar to the theoretical calculation results of the stainless steel bar constitutive model. Considering the convenience of this calculation and verification, the steel constitutive model in China's current code is used to carry out the calculation. However, the calculation of the load-bearing capacity of the stainless steel bar eccentric compression member is more appropriate. Subsequently, China's normative model is revised to render the calculation results more relevant and provides a safety reserve. Formulas (6) and (7) are used to revise the standard model, and the revised results are shown in Table 7 . It can be 


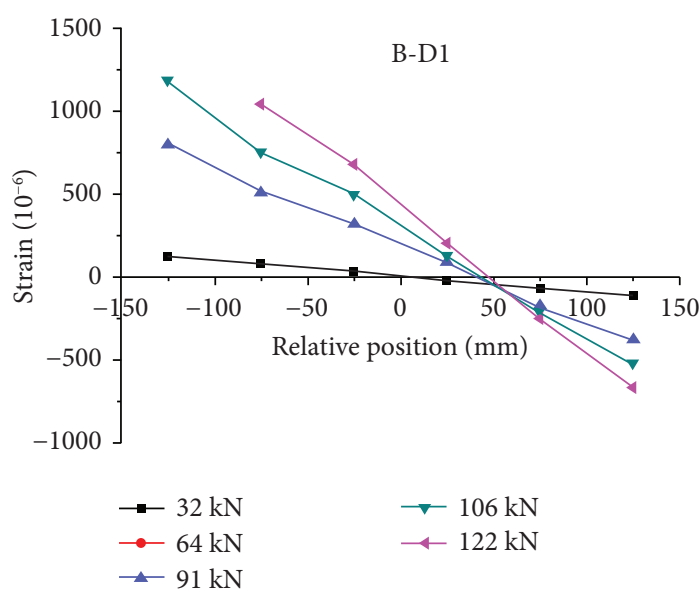

(a)

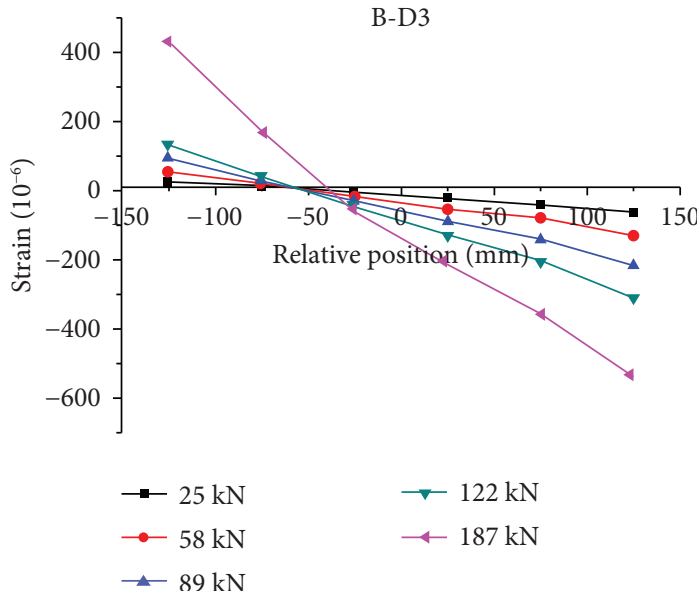

(c)

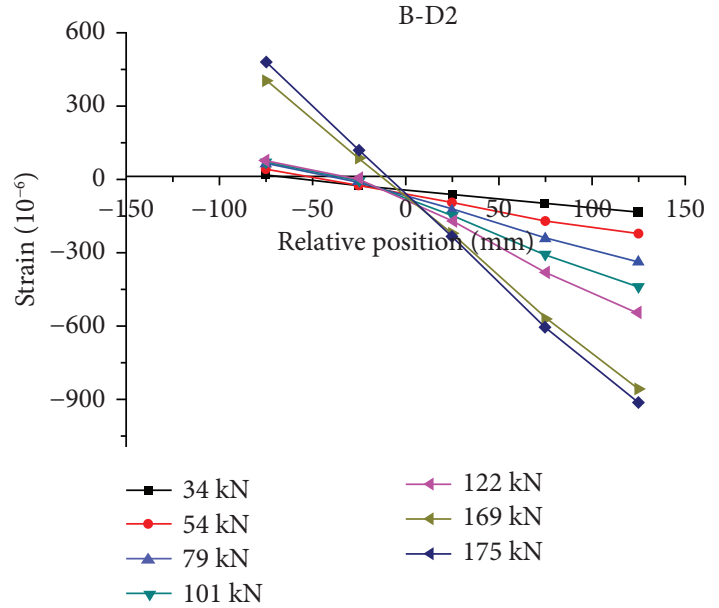

(b)

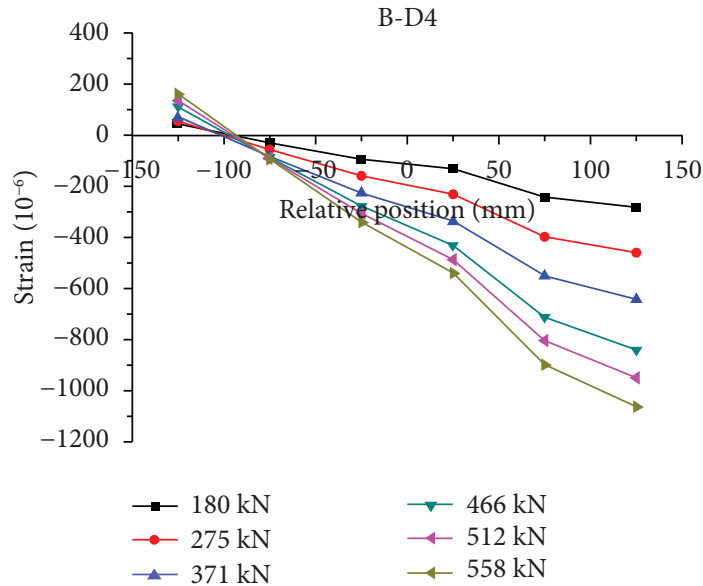

(d)

FiguRE 11: Strain-load relationship diagram of concrete.

TABLE 5: Mechanical properties of stainless steel bars.

\begin{tabular}{lcccc}
\hline$\varepsilon_{0.2}$ & $\sigma_{0.2}$ & $\varepsilon_{u}$ & $\sigma_{u}$ & $E_{s}$ \\
\hline 0.0061 & $605 \mathrm{MPa}$ & 0.276 & $797 \mathrm{MPa}$ & $151 \mathrm{GPa}$ \\
\hline
\end{tabular}

TABLe 6: Mechanical indexes of stainless steels.

\begin{tabular}{lcccc}
\hline Specimen number & \multicolumn{2}{c}{ Ultimate bearing capacity, $N_{u} / \mathrm{kN}$} \\
& Standard model & Test value & Failure pattern \\
\hline A-D1 & 249.51 & 263.15 & 242.2 & Large eccentricity \\
A-D4 & 856.08 & 850.84 & 807.2 & Small eccentricity \\
B-D1 & 337.02 & 284.23 & 302.1 & Large eccentricity \\
B-D2 & 438.28 & 415.78 & 440.5 & Large eccentricity \\
B-D3 & 745.62 & 730.30 & 625.4 & Small eccentricity \\
B-D4 & 979.74 & 964.62 & 952.0 & Small eccentricity \\
C-D1 & 640.03 & 633.03 & 653.5 & Large eccentricity \\
C-D4 & 1093.04 & 1084.65 & 1032.0 & Small eccentricity \\
\hline
\end{tabular}


TABLE 7: Comparison of the calculated value and test value of load-bearing capacity of the revised standard mode.

\begin{tabular}{|c|c|c|c|}
\hline \multirow{2}{*}{ Specimen number } & \multicolumn{2}{|c|}{ Ultimate bearing capacity $N_{u} / \mathrm{kN}$} & \multirow{2}{*}{ Ratio of test to calculated value } \\
\hline & Revised specification model & Test value & \\
\hline A-D1 & 263.15 & 242.2 & 1.0865 \\
\hline A-D4 & 805.97 & 807.2 & 0.9985 \\
\hline B-D1 & 284.23 & 302.1 & 0.9408 \\
\hline B-D2 & 415.78 & 440.5 & 0.9439 \\
\hline B-D3 & 684.01 & 625.4 & 1.0937 \\
\hline B-D4 & 915.27 & 952.0 & 0.9614 \\
\hline C-D1 & 633.03 & 653.5 & 1.7958 \\
\hline $\mathrm{C}-\mathrm{D} 4$ & 1025.77 & 1032.0 & 0.9940 \\
\hline
\end{tabular}

seen in Table 7 that the error between the theoretical calculation value and the test value of the modified stainless steel eccentric compression specimen's bearing capacity is small. Within a reasonable range, formulas (6) and (7) can be used to modify the standard model.

For small eccentric compression members, when calculating the bearing capacity, the formula for calculating the strength of the eccentric compression concrete column is shown in (6). To complete the calculation, formula (6) is added to formula (5) and the small eccentric compression of the stainless steel is calculated. The theoretical calculated bearing capacity of the compression test piece is shown in Table 7.

$$
f_{c}=0.76 f_{c u}-\alpha .
$$

For large eccentric compression members, the following calculation formula is used when calculating the bearing capacity to obtain the calculated theoretical bearing capacity value of SSRC columns, under large eccentric compression. The calculation results are shown in Table 7 .

$$
\left\{\begin{array}{l}
N=f_{c} b x+\beta\left(\sigma_{s}^{\prime} A_{s}^{\prime}-\sigma_{s} A_{s}\right), \\
N e=f_{c} b x\left(h_{0}-\frac{x}{2}\right)+\sigma_{s}^{\prime} A_{s}^{\prime}\left(h_{0}-a_{s}^{\prime}\right) .
\end{array}\right.
$$

Here, $\alpha=1.5$ and $\beta=0.8$.

\section{Conclusions}

In this paper, eight stainless steel bar compression components are fabricated and tested. Based on the test results, the mechanical properties of the SSRC column are analyzed and the calculation formula of the bearing capacity of the SSRC eccentric compression members is proposed. The factors affecting the bearing capacity of the SSRC column are analyzed. The main conclusions are as follows:

(1) The failure mode of SSRC eccentric compression column in the ultimate state is the same as that of the ordinary concrete column. When large eccentric compression member destruction occurs, the concrete in the compression zone is crushed. However, the stainless steel bars in the compression zone did not yield, whereas the stainless steel bars in the tensile zone did. The lateral deflection of the specimen is relatively large, and it displayed characteristics of ductile failure. In the case of small eccentric compression member failure, the stainless steel bars near the loading point yielded, while the stainless steel bars furthest from the loading point did not. The lateral deflection of the specimen is relatively small, which indicates that it is a brittle failure.

(2) The deflection-load curve of the eccentric compression column of stainless steel bars can be more or less divided into the following three stages: linear elastic stage, nonlinear ascending stage, and descent stage. Compared with small eccentricity, the descending section of the large eccentricity compression member is relatively gentle and the ductility of the specimen is superior. In the case of large eccentric compression-when the specimens are in the same load-the smaller the reinforcement ratio, the greater the deflection. In the case of small eccentric compression, the change in reinforcement ratio of the longitudinal stainless steel bars has little effect on the deflection of the specimens. When other conditions are comparable, the deflection corresponding to the ultimate load of the SSRC column rises with the increase in eccentricity and the loaddeflection curve is gentler.

(3) The strain distribution of the mid-span section of the SSRC column with small eccentric pressure is consistent with the assumption of the plane section along the height, which can be theoretically calculated according to the plane section assumption.

(4) The Rasmussen model and the current model, adopted with the Chinese specifications, are the two types of stainless steel reinforcement constitutive models currently most commonly used. The formula of the specification model is simple and easy to calculate, allowing for the modification of the specification model. According to the comparison of the revised and test results, the conclusions indicate that the correction formula can be used in the stainless steel bearing capacity calculation for reinforced concrete eccentric pressure column. The calculated results are representative of the test values. 
Although this paper has done a lot of research on the mechanical properties of SSRC eccentric pressure members, because of the complexity of SSRC structure and the discrete nature of the concrete material test, there are still many problems to be solved: (1) Explore the size effect of concrete structure on SSRC to solve whether the construction of large-volume SSRC can be used to analyze the current relevant theories. (2) Search the suitable type of concrete structure in which the strength of stainless steel bars can play out to the greatest extent. (3) Carry out the experimental research about the flexural, shear, and fatigue resistance of stainless steel reinforced concrete structure. For the application and development of stainless steel bars in practical engineering, more comprehensive research and comparison are needed.

\section{Data Availability}

The data used to support the findings of this study are available from the corresponding author upon request.

\section{Conflicts of Interest}

The authors declare that there are no conflicts of interest regarding the publication of this paper.

\section{Acknowledgments}

This research was funded by the National Natural Science Foundation of China, under grant number 51679220.

\section{References}

[1] J. Zhang, C. Li, and X. Zheng, Research on Stainless Steel Reinforcement Concrete Structure, People's Communications Press, Beijing, China, 2015.

[2] H. Geng, Experimental Study on Mechanical Properties of Stainless Steel Reinforcement and Structure for Bridge, Zhengzhou University, Zhengzhou, China, 2013.

[3] J. Wang, "Research on the causes of steel bar corrosion and anti-corrosion design in concrete," Concrete, no. 8, pp. 41-42, 2008.

[4] G. J. Van den Berg and A. H. Liang, "Study on SSRC," Architectural Technology, vol. 31, no. 2, p. 105, 2000.

[5] J. Wang, Study on Bonding Properties of Stainless Steel Reinforcement to concrete, Zhengzhou University, Beijing, China.

[6] B. Hu, Research on Compression Performance of FRP Constrained concrete Columns, Hefei University of Technology, Hefei, China, 2010.

[7] G. Zhang and M. Wu, "Application and development of SSRC," Journal of Foshan University of Science and Technology (Natural Science Edition), vol. 24, no. 2, pp. 10-13, 2006.

[8] G. Zhang, Y. Xu, and Z. Ding, "Experimental study on flexural performance of SSRC beams," Railway Construction, no. 2, pp. 13-15, 2008.

[9] G. Zhang, F. Zhao, and Z. Zhang, "Experimental study on seismic behavior of SSRC beams," China Railway Science, vol. 31, no. 5, pp. 35-40, 2010.

[10] J. Huang, Experimental Study on Fatigue Behavior of SSRC Bridge Beams, Guangdong University of Technology, Guangdong, China, 2013.
[11] G. Zhang, C. Wang, and J. Huang, "Nonlinear analysis on SSRC columns under low-cyclic load," Applied Mechanics and Materials, vol. v256-259, pp. 588-591, 2013.

[12] Y. Xu, Experimental Study on Mechanical Properties of SSRC Beams, South China University of technology, Guangdong, China, 2007.

[13] H. Yuan, Y. Wang, and Y. Shi, "Preliminary study and application prospect of SSRC," Architectural Science, vol. 27, no. 5, pp. 101-105, 2011.

[14] H. Geng, Experimental Study on Mechanical Properties of Stainless Steel Bars and Members for Bridges, Zhengzhou University, Zhengzhou, China, 2013.

[15] L. Chen, Y. Qu, and Y. Tang, "Critical chloride concentration of stainless steel reinforcement," Corrosion \& Protection, vol. 35, no. 5, pp. 446-449, 2014.

[16] C. Li, W. He, and J. Lu, "Bonding performance between stainless steel reinforcement and concrete," Highway Communication Technology, vol. 33, no. 12, pp. 15-20, 2016.

[17] H. Wang, J. Ling, and X. Sun, "Experimental study on corrosion resistance of carbon steel bars and stainless steel bars in simulated concrete pored fluid," West China Communications Science and Technology, no. 2, pp. 66-69, 2018.

[18] Y. Zhou, D. Zou, and H. Wang, "Corrosion law of carbon steel stainless steel connection in concrete simulation solution," Concrete, no. 1, 2018.

[19] C. Xu, Y. Yuan, and B. Lu, “Anchorage design and reliability analysis of duplex stainless steel bars and concrete," Journal of Shenyang Jianzhu University (Natural Science Edition), vol. 35, no. 3, pp. 445-452, 2019.

[20] P. Borges, E. Moreno, A. Acosta, A. Knudsen, O. Rincon, and M. Madrid, Inspecting a Half-century Reinforced concrete Pier Made with Stainless Steel Reinforcement in Mexico, 2002.

[21] Z. Zhang and Q. Zheng, Corrosion Resistant Stainless Steel Bars, Foreign bridges, Punjab, India, 1997.

[22] X. Xu, Research Trends of Stainless Steel Bars Abroad, Shandong building materials, Shandong, China, 2000.

[23] D. McDonld, M. Sherman, and D. Pfeier, "Stainless steel reinforcing as corrosion protection," Concrete International, vol. 17 , no. $5,1995$.

[24] L. Bertolini, P. Pedeferri, and T. Pastore, "Stainless steel in reinforced concrete structures," in Proceedings of the 2nd International Conference under Severe Conditions, v01, Tromso, Ed., pp. 21-24pp. 21-, Rome, Italy, June 1998.

[25] C. Abreu, M. Cristobal, M. Montemor, and X. Novoa, "Galvanic coupling between carbon steel and austenitic stainless steel in alkaline media," vol. 47, no. 13, pp. 2271-2279, 2002.

[26] H. Castro, C. Rodriguez, F. J. Belzunce, and A. F. Canteli, "Mechanical properties and corrosion behaviour of stainless steel reinforcing bars," Journal of Materials Processing Technology, vol. 143-144, pp. 134-137, 2003.

[27] G. Blanco, A. Bautista, and H. Takenouti, "EIS study of passivation of austenitic and duplex stainless steels reinforcements in simulated pore solutions," Cement and Concrete Composites, vol. 28, no. 3, pp. 212-219, 2006.

[28] K. Milan, N. Pavel, and B. Martin, "Threshold chloride concentration for stainless steels activation in concrete pore solutions," Cement and Concrete Research, vol. 40, no. 3, pp. 431-436, 2010.

[29] C. Hansson, M. Islam, and B. Bergsma, "Chloride induced corrosion behavior of stainless steel and carbon steel reinforcing bars in sound and cracked concrete," Corrosion Houston Tx, vol. 69, no. 3, pp. 303-312, 2013.

[30] M. Gastaldi and L. Bertolini, "Effect of temperature on the corrosion behaviour of low-nickel duplex stainless steel bars 
in concrete," Cement and Concrete Research, vol. 56, pp. 52-60, 2014.

[31] E. Medina, J. M. Medina, A. Cobo, and D. M. Bastidas, "Evaluation of mechanical and structural behavior of austenitic and duplex stainless steel reinforcements," Construction and Building Materials, vol. 78, pp. 1-7, 2015.

[32] L. Gardner, Y. Bu, P. Francis, N. R. Baddoo, K. A. Cashell, and F. McCann, "Elevated temperature material properties of stainless steel reinforcing bar," Construction and Building Materials, vol. 114, pp. 977-997, 2016.

[33] Y. Bu and L. Gardner, "Finite element modelling and design of welded stainless steel I-section columns," Journal of Constructional Steel Research, vol. 152, pp. 57-67, 2019.

[34] C. Bemfica, L. Carneiro, E. N. Mamiya, and F. C. Castro, "Fatigue and cyclic plasticity of 304L stainless steel under axial-torsional loading at room temperature," International Journal of Fatigue, vol. 125, pp. 349-361, 2019.

[35] H. Wang, Application And Discussion Of Stainless Steel Reinforcement In Bridge Construction At Home And Abroad, 2016.

[36] N. Ireland, Use Of Stainless Steel Reinforcement In Highway Structures, Stationery Office, London, UK, 2001.

[37] D. V. V al and M. G. Stewart, "Life-cycle cost analysis of reinforced concrete structures in marine environments," Structural Safety, vol. 25, no. 4, pp. 343-362, 2003.

[38] N. Frank and P. Smith, "Stainless steel reinforcement for concrete construction," in Proceedings of the 12th Middle East Conference and Exhibition, Rome, Italy, June 2008.

[39] A. Cope, Q. Bai, A. Samdariya, and S. Labi, "Assessing the efficacy of stainless steel for bridge deck reinforcement under uncertainty using Monte Carlo simulation," Structure and Infrastructure Engineering, vol. 9, no. 7, pp. 634-647, 2013.

[40] A. Younis, U. Ebead, S. Judd, and S. Judd, "Life cycle cost analysis of structural concrete using seawater, recycled concrete aggregate, and GFRP reinforcement," Construction and Building Materials, vol. 175, pp. 152-160, 2018.

[41] Dalian University of technology, Hydraulic Reinforced concrete Structure, China Water \& Power Press, Beijing, China, 4th edition, 2012.

[42] J. Ye and G. Li, Principles of Structural Design, China Communication Press, Beijing, China, 4th edition, 2018.

[43] D. Mao, Study on Mechanical Behavior of $500 \mathrm{MPa}$ Reinforced concrete Compression Members, Zhengzhou University, Zhengzhou. China, 2008.

[44] B. Li, Strength and Ductility of Reinforced Concrete and Frames Constructed Using High-Strength Concrete, University of Canterbury, Christchurch, New Zealand, 1994.

[45] C. Ma, X. Li, and L. Wang, "Stress analysis of steel reinforced high strength concrete eccentrically loaded columns," Journal of Shenyang Architecture University (Natural Science Edition), vol. 22, no. 3, pp. 388-392, 2006.

[46] J. Pan, W. Wang, and X. Jin, "Study on characteristics of FRP confined reinforced concrete short columns under eccentric load," China Civil Engineering Journal, vol. 38, no. 2, pp. 46-50, 2005.

[47] Q. Wang and G. Zhao, "Experimental study on ductility of high strength concrete columns," Journal of building structure, vol. 16, no. 4, pp. 22-31, 1995.

[48] P. H. Chuang and S. K. Kong, "Strength of reinforced concrete columns," Journal of Structural Engineering, vol. 124, no. 9, pp. 992-998, 1998.

[49] X. Sun, X. Fang, and L. Guan, Mechanics of Materials, Higher Education Press, Beijing, China, 5th edition, 2009.
[50] K. J. R. Rasmussen, "Full-range stress-strain curves for stainless steel alloys," Journal of Constructional Steel Research, vol. 59, no. 1, pp. 47-61, 2003. 